\title{
ORGANIZATIONAL CULTURE \&
} EMPLOYEE BEHAVIOR

\author{
Case study
}

\author{
LAHTI UNIVERSITY OF APPLIED \\ SCIENCES \\ Degree programme in \\ Business Information Technology \\ Thesis \\ Spring 2015 \\ Tianya LI
}


Lahti University of Applied Sciences

Degree Programme in Business Information Technology

Tianya LI:

ORGANIZATIONAL CULTURE \& EMPLOYEE BEHAVIOR

Case Study

Bachelor's Thesis in Business Information Technology, 44 pages, 3 pages of appendices

Spring 2015

ABSTRACT

Organizations are among the key units of the society. During their establishment and development, a specific kind of organizational culture eventually appears. The purpose of organizational culture is to improve solidarity and cohesion, and to stimulate employees' enthusiasm and creativity to improve the organization's economic efficiency. In addition, organizational culture greatly influences employee behavior.

The aim of this study is to find out how organizational culture affects employee behavior. It is important to understand that in order to improve the organization's business management and let the organizational culture have the right impact on employees.

The results of the study indicate that organizational culture mainly impacts motivation, promotes individual learning, affects communication, and improves organizational values, group decision making and solving conflicts.

Keywords: Organizational culture, organizational behavior, employee behavior. 


\section{CONTENTS}

1 INTRODUCTION 1

1.1 Background 1

1.2 Statement of the problem 1

1.3 Overview of the thesis 2

2 RESEARCH METHODOLOGY 4

$\begin{array}{lll}2.1 & \text { Research question } & 4\end{array}$

2.2 Research methods 4

2.3 Research framework 5

$2.4 \quad$ Data collection and data analysis 5

3 LITERATURE REVIEW

$\begin{array}{lll}3.1 & \text { Organizational culture: an overview } & 7\end{array}$

3.2 Organizational culture and its dimensions 9

3.2.1 Power Distance 9

$\begin{array}{ll}\text { 3.2.2 Individualism and collectivism } & 10\end{array}$

3.2.3 Masculinity and Femininity 11

$\begin{array}{lll}3.2 .4 & \text { Uncertainty avoidance } & 13\end{array}$

3.2.5 Long-Term Orientation 14

3.2.6 Indulgence versus Restraint 14

$\begin{array}{lll}3.3 & \text { Organizational behavior } & 14\end{array}$

3.3.1 Individual level variables 15

3.3.2 Group level variables 15

3.3.3 Organizational system level variables 15

$3.4 \quad$ Organizational culture and organizational behavior $\quad 16$

3.5 Advantages organizational culture has on behavior 17

4 CASE STUDY 19

4.1 Case Overview 19

4.2 Organizational culture 19

$\begin{array}{lll}\text { 4.2.1 Symbols } & 20\end{array}$

$\begin{array}{lll}4.2 .2 & \text { Rituals } & 21\end{array}$

$\begin{array}{lll}4.2 .3 & \text { Values } & 23\end{array}$

$\begin{array}{lll}4.3 & \text { Culture dimensions measurement } & 23\end{array}$

$\begin{array}{lll}\text { 4.3.1 Power distance } & 24\end{array}$

4.3.2 Individualism and collectivism 25 
$\begin{array}{lll}\text { 4.3.3 Uncertainty avoidance } & 27\end{array}$

4.3.4 Masculinity and femininity 28

4.3.5 Long-term orientation 29

4.3.6 Indulgence and restraint 30

5 DATA ANALYSIS 31

6 CONCLUSION 39

7 DISCUSSION 41

7.1 Limitations 41

7.2 Validity and reliability 41

$\begin{array}{lll}7.3 & \text { Suggestions for future study } & 42\end{array}$

REFERENCES 43

APPENDICES $\quad 45$ 


\section{LIST OF FIGURES}

Figure 1: Structure of the thesis 3

Figure 2: The "Onion": Manifestations of culture at different levels of depth 8

Figure 3: Structure diagram of organizational culture 20

Figure 4: Logo of case company $\quad 21$

Figure 5: Relations between dimensions and a given value 23

Figure 6: Organizational structure of the case company 24 


\section{LIST OF TABLES}

Table 1: Key differences between small- and large-power-distance cultures ....... 10

Table 2: Key differences between collectivist and individualist cultures ............. 11

Table 3: Key differences between feminine and masculine cultures ................... 12

Table 4: Key differences between weak and strong uncertainty avoidance .......... 14

Table 5: Interviewees' answers concerning power distance................................ 32

Table 6: Interviewees' answers concerning individualism and collectivism ........ 33

Table 7: Interviewees' answers concerning masculinity and femininity................34

Table 8: Interviewees' answers concerning uncertainty avoidance ......................35

Table 9: Interviewees' answers concerning long-term orientation.........................37

Table 10: Interviewee's answers from question theme indulgence and restraint ...38 


\section{INTRODUCTION}

\subsection{Background}

Culture has been defined in many different ways and by many different theorists. For instance, according to Geert et al (2010) "it is the collective programming of the mind that distinguishes the members of one group or category of people from others". Kotter and Heskett (1992) noted that culture is "a set of beliefs, values and behaviors commonldy held by a society, being derived from social anthropology as a framework for understanding 'primitive' societies". Finally, Deal and Kennedy (1982) defined culture in short as "the way we do things around here".

When establishing and developing a company or other organization, an internal culture will develop step by step. The purpose of its existence is to improve solidarity and cohesion, stimulate employees' enthusiasm and creativity, and to improve the economic efficiency of an organization. Like cultures in general, organizational cultures are complex and unique. They are based their individual history, leadership and workforce.

Hence, in order to improve management and let an organizational culture have the right effect on employees, it is important to understand how organizational-cultures affect employee behavior.

\subsection{Statement of the problem}

For an organization, employee is its basic constituent units, and culture is the common value and code of conduct shared by the employees. It could give can provide employees with a relaxed working environment with harmonious interpersonal relationships in order to give full play to their ability. A corporate culture allows employees to have a sense of mission and feel responsibility, and work towards the overall goal of the company.

The competitiveness of enterprises is not only reflected in the technology, but also in their corporate culture. A positive organizational culture can promote healthy development of an enterprise, and actively mobilize the performance of employees, 
and make them work with more enthusiasm. Moveover, it may improve production efficiency. In short, the benefits of a positive organiziational culture are self evident.

The priority of an enterprise is to increase the loyalty of its customer base. Therefore, a good corporate image must be established. In other words, a good corporate image brings good economic returns, and a good corporate image is dependent on good organizational culture.

\subsection{Overview of the thesis}

This study consists of six chapters. First, the research problem is in traduced. In addition, this section provides a contextual background and outlines some of the main aspects of organizational cultures and behavior. Finally, the importance of the research problem is explained and the research question is introduced.

Chapter two explores the research approach adopted in this study, includes the research question, defines the research method, and describes the research framework, and data collection and analysis.

Chapter three presents a literature review, which introduces previous studies about organizational culture, employee behavior in organizations, and the relations among them.

Chapter four includes a case study on the effects of organizational culture. The chapter presents an overview of the case company, discusses organizational culture and introduces culture dimension measurement.

Chapter five introduces the data collection method and data analysis. Data will be collected from interviews and observation. Some of the employees and supervisor from management levels in the case company will be interviewed.

Chapter six presents the results of the data analysis, findings and a conclusion to the research question. The factors that influence the employee behavior in the case company will be summarized to give an answer to the research question. 
Finally, chapter seven outlines the limitations, the validity and reliability of the study, and introduces suggestions for future studies.

The following figure (Figure 1) shows the structure of the thesis:

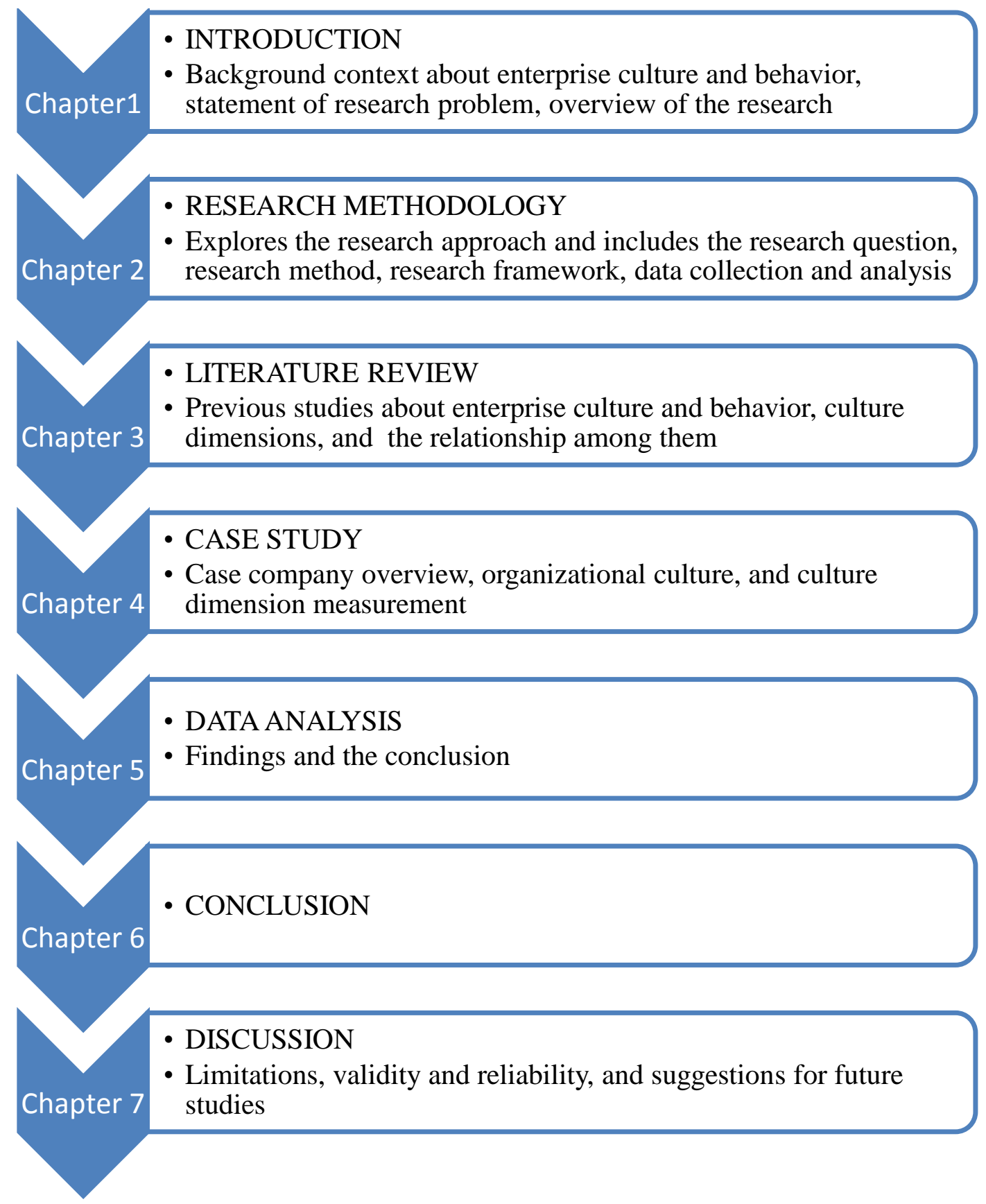

Figure 1: Structure of the thesis 


\section{RESEARCH METHODOLOGY}

\subsection{Research question}

It is important to examine how enterprise culture may affect employee behavior. The study therefore focuses on the culture dimensional factors that influence employee behavior and may improve work efficiency and productivity. Thus, the research question is:

How does organizational culture affect employee behavior?

\subsection{Research methods}

In this study, the research will be conducted using a qualitative research method. When applying qualitative methods, the aim is to reach a thorough understanding of the object of study based on people's behavior, feelings and experiences. The data is often collected by interviews rather based on statistics and numbers.

As the present study focuses on people, their behaviors and how organizational culture affects their behavior, the research question cannot be answered on the basis of numerical data. Thus, qualitative research methods are considered suitable for the purposes of this study.

This is a deductive, explanatory study. The deductive approach is concerned with examining a hypothesis based on existing theory. By applying relevant methodology, a given study either confirms or disproves a hypothesis. Generally, studies using deductive approach follow the following stages: Theory, Hypothesis, Observation, and Confirmation. (Woodwell, 2014)

The hypothesis deduced by the researcher is that the employee behavior is affected by the three levels of the culture: symbols, rituals, and values. In addition, values consists with six culture dimensions, power distance, individualism and collectivism, masculinity and femininity, uncertainty avoidance, long-term orientation, and indulgence and restraint. 


\subsection{Research framework}

In this research framework, the concepts are based on the background information, the literature review and the case study. The first concept is organizational culture. It is a system of shared meanings that distinguishes the organization from other organizations. This system of shared meanings represents an organizational core value and has a close association with organizational behavior. In this study, the term "enterprise culture" is synonymous with the widely used concept of organizational culture.

The second key concept is culture dimension. It was coined by Professor Geert Hofstede, and it aims to analyse how values in the workplace are influenced by culture. It is also an important part of understanding organizational behavior.

The third key concept is organizational behavior. It defines how individuals and groups behave in organizations. The purpose is to apply this knowledge in improving an organization's effectiveness.

Based on the second and third concept, concept four is the relationship between culture dimensions and organizational behavior. It gives an idea of how enterprise culture affects organizational behavior.

By applying these four concepts, this research framework can answer the research question: How does organizational culture affects employee behavior?

\subsection{Data collection and data analysis}

This study is focused on identifying the factors in culture that affect employee behavior. Thus, interviewing and observation are the primary data collection method used in this study.

The interviews will hold conducted online and with different people in the company to ensure reliability. The interview will be unstructured to allow flexibility. Moreover, unstructured interview allows the interviewee to be comfortable and talk freely. (James, 2012) 
The interviewees will be selected randomly among the employees in case company "JUNHE". Since culture is the main factor that affects the employee behavior, the researcher will ask questions related to cultures and values.

Observation is a type of correlational research in which a researcher observes ongoing behavior in order to study natural phenomena. One of the advantages of observation is that it is flexible and it measures behavior directly, not through reports or records.

Since the researcher used to be an employees in the case company, and participated numerous projects within groups and individually, observation will be quite fair. The behavior of the case company's employees will be observed according to three levels: at an individual, a group, and an organizational level. The observation sustained from the start to the end of their work in a day, including regular lunchtime and breaks. The researcher will record their behavior as evidence for further studies. In addition, the observation also covers the symbols and rituals within the case company.

The observation and interview data will be interpreted and summarized according to the three levels of the culture: symbols, rituals, and values. The researcher will analyse the collected data by identifying the impacts from each level. In order to interpret the values in cultures, the researcher will elaborate Hofstede's cultural dimensions theory from all the resources, and apply it in the case company to identify the factors that affect employee behavior. Finally, the researcher will analyse the case study to deduce a hypothesis and draw a conclusion. 


\section{LITERATURE REVIEW}

\subsection{Organizational culture: an overview}

Organizational culture is now a prevalent topic among managers, among consultants and among academics. As a mean of distinguishes the members of one group from others, enterprise culture gives identities to organizations, groups and individuals.

There is no single definition for the concept of the organizational culture. Instead, there are several. For instance, "the process of thinking helps in establishing one member from another on the basis of cognitive thinking" (Geert, et al., 2010); "the success guidance based upon different values and norm that makes culture effective" (Schein, 2004); "the set of beliefs, behavior, norms and values helps in making culture most effective" (Kotter, et al., 1992).

Even if there is no single definition for the concept of the organizational culture and even if cultures are very different from one to another, commonalities do exist. Hofstede (2010) introduced an onion model to cover the total concept of culture, including four aspects: symbols, heroes, rituals, and values. In Figure 2, those aspects represent the skins of an onion, indicating that symbols represent the surface and value the deepest manifestation of the culture with heroes and rituals in between.

The most superficial level is symbols. Symbols include words, pictures, architecture, service models, or other objects that carry a particular meaning that is recognized as such only by those who share the culture. The reason why symbols are the most superficial level of the onion model is that symbols are the material carriers of the culture; they can easily be replaced by another system.

Heroes are persons who carry characteristics that are highly recognized. Heroes are immortal, and they can serve as models for showing the correct values. 
Rituals include social behavior, discourse, and the way language is used. Rituals are collective activities that are used to express kinds of emotions such as respect.

Within a culture, rituals are considered socially essential.

The core of culture, according to Figure 2 is formed by values. Values mainly refer to fundamental beliefs, values, ethics and spirits of an organization.

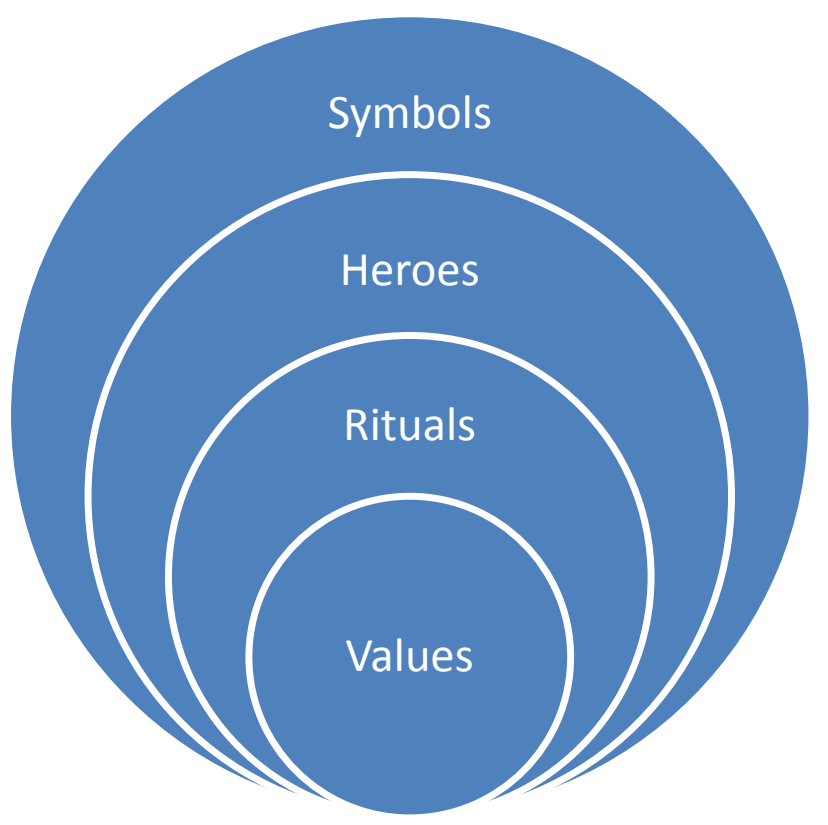

Figure 2: The "Onion": Manifestations of culture at different levels of depth

Robbins (2010) outlines seven primary characteristics that capture the essence of an organizational culture as follows: (1) Innovation and risk taking. Employees are encouraged to be creative and take risks which produce creativity. Innovation is also a form of productivity. (2) Attention to detail. Employees are expected to be attentive. Details always determine success or failure. (3) Outcome orientation. Management focuses on final outcomes or the processes used to achieve those goals. (4) People orientation. The consideration in management decisions tends to affects people within the organization. (5) Team orientation. A work event is organized among teams or individuals. (6) Aggressiveness. A person is aggressive and competitive or easy-going during work. (7) Stability. Organization is looking forward to maintaining the status quo or keeps growing. 
Nowadays organization culture has generally been associated with management (Kotter, et al., 1992). Schein (1995) pointed that there are two essential factors that have influence on effective culture management: structural stability and integration of superior standard of organization culture.

\subsection{Organizational culture and its dimensions}

In an attempt to find characteristics of culture that might have influence on business behavior, Geert Hofstede implemented one of the most comprehensive studies of how values in the workplace are influenced by culture. He analysed a large database of employee value scores collected within IBM between 1967 and 1973. In addition, he demonstrated that there are national and regional cultural groupings that affect the behavior of organizations and identified four dimensions of culture (later six) in his study of cultures:

- Power distance

- Individualism

- Uncertainty avoidance

- Masculinity

Based on research by Michael Harris Bond, and Confucian thinking, a fifth dimension was identified by Hofstede in 1991: Long-Term Orientation.

A sixth dimension was added in the 2010, based on Michael Minkov's analysis of the World Values Survey data. This new dimension is called Indulgence versus Restraint.

\subsubsection{Power Distance}

Power distance is the first dimension addressed by Hofstede; it reflects the inequality of society. Some people have more power than others, while some people have more social status and respect than others. It reflects such inequalities among the various areas of the society. Despite this, different societies find different solutions to deal with social inequality. According to Hofstede's research, not all societies regard inequality as a problem. 
In the workplace, power inequality of the "boss-subordinates relationships" is objective. In the large-power-distance situation, supervisors and subordinates consider each other as existentially unequal. Organizations centralize power in top management as much as possible. In the small-power-distance situation, subordinates and supervisors consider each other as existentially equal; the hierarchical system, established for convenience. Organizations are fairly decentralized, with flat hierarchical pyramids and limited numbers of supervisory personnel.

Table 1 summarizes the key differences in the workplace between small- and large-power-distance cultures.

\section{Key differences between small-power-distance and large-power-distance cultures}

\begin{tabular}{l|l} 
Small power distance & Large power distance
\end{tabular}

\begin{tabular}{l|l} 
Decentralization is popular. & Centralization is popular. \\
\hline Managers rely on their own experience. & Managers rely on formal rules.
\end{tabular}

Subordinates expect to be consulted.
do.

Subordinate-superior relations are Subordinate-superior relations are pragmatic. emotional.

\section{Privileges are unacceptable. $\quad$ Privileges are normal.}

Table 1: Key differences between small- and large-power-distance cultures

\subsubsection{Individualism and collectivism}

Individualism and collectivism is the second dimension addressed by Hofstede. In this dimension differences between organization interest and self interest has perfectly been matched. Hofstede (2010) indicated that in collective cultures, the interest of a group or organization is valued more than the interest of an individual. 
In contrast, in an individualist society, an individual's interests are valued over the interests of a group. Hofstede also states the idea that society's expectations in terms of individualism or collectivism are reflected by employees in the organizations.

In the workplace, employees in an individualist culture are expected to act according to their own interests, and the objectives of work should be organized in such a way that they match the individual's interests. In a collectivist culture, individuals belong to in-groups. The employees act according to the interests of this in-group, which may not always match with his or her individual interests. Risks could be reduced when hiring someone already known.

Table 2 summarizes the key differences in the workplace between collectivist and individualist cultures.

\section{Key differences between collectivist and individualist cultures}

$\begin{array}{ll}\text { Collectivism Individualism } & \text { Ind }\end{array}$

Employees pursue the in-group's
interest.

Employees pursue the employer's interest.

Hiring and promotion decisions Hiring and promotion decisions are concidering in-group members. The relationship between employees is basically moral.

The internet and email are less attractive and less frequently used. based on skills and performance.
The relationship between employees is established with a contract.

The internet and email hold strong appeal and are frequently used to link individuals.

Table 2: Key differences between collectivist and individualist cultures

\subsubsection{Masculinity and Femininity}

Masculinity and femininity reflect whether a certain society is predominantly male or female in terms of cultural values, gender roles and power relations. Every 
human society consists of males and females, usually in approximately equal numbers. They are biologically distinct. Males are relatively taller and stronger. At the same time, females are thinner and more agile.

In masculine cultures, some occupations were structured based on genders, which means some jobs are given to males and others to females. There is also a stronger emphasis on achievements, growth and challenge in jobs. In these cultures, people emphasize job performance more than individual interests. Additionally, people prefer to receive money, titles or other materialistic or status-oriented rewards. On the contrary, in feminine cultures, good working conditions and job satisfaction are preferred. Meaningful rewards are leisure time, improved benefits or symbolic rewards.

Table 3 summarizes the key differences in the workplace between feminine and masculine cultures.

\begin{tabular}{|c|c|}
\hline \multicolumn{2}{|c|}{ Key differences between feminine and masculine cultures } \\
\hline Femininity & Masculinity \\
\hline $\begin{array}{l}\text { Management based on intuition and } \\
\text { consensus. }\end{array}$ & $\begin{array}{l}\text { Management based on decisive and } \\
\text { aggressive actions. }\end{array}$ \\
\hline $\begin{array}{l}\text { Resolution of conflicts by compromise } \\
\text { and negotiation. }\end{array}$ & $\begin{array}{l}\text { Resolution of conflicts by letting the } \\
\text { strongest win. }\end{array}$ \\
\hline Reward system is based on equality. & Reward system is based on equity. \\
\hline People work in order to live. & People live in order to work. \\
\hline $\begin{array}{l}\text { More leisure time is preferred over more } \\
\text { money }\end{array}$ & $\begin{array}{l}\text { More money is preferred over more } \\
\text { leisure time }\end{array}$ \\
\hline
\end{tabular}

Table 3: Key differences between feminine and masculine cultures 


\subsubsection{Uncertainty avoidance}

Uncertainty avoidance is the fourth dimension of the Hofstede's culture dimension theory. All human beings have to face the fact that we do not know what will happen tomorrow, thus, every human society has developed ways to deal with it. The ways belong to the domains of technology, law and religion. Technology, from the most primitive to the most advanced, helps people to avoid uncertainties caused by nature. Laws try to prevent uncertainties in the behavior of other people.

Religion is a way of relating to the transcendental forces that are assumed to control people's personal future.

In a strong uncertainty avoidance culture, people prefer rules, regulations, and the conservative legal order, and do not like adventure and innovation. In order to avoid risks, they prefer stable jobs, a secure life, avoidance of conflict, and have a lower tolerance for deviant persons and ideas. In contrast, in a week uncertainty avoidance culture, conflicts and competitions are acceptable.

Table 4 summarizes the key differences in the workplace between weak and strong uncertainty avoidance cultures.

\section{Key differences between weak and strong uncertainty avoidance cultures \\ $\begin{array}{ll}\text { Weak uncertainty avoidance } & \text { Strong uncertainty avoidance }\end{array}$ \\ There should be no more rules than There is an emotional need for rules, strictly necessary. $\quad$ even if they will not work. \\ Work hard only when needed. There is an emotional need to be busy and an inner urge to work hard. \\ Time is a framework for orientation. $\quad$ Time is money. \\ Tolerance for ambiguity and chaos. Need for precision and formalization. \\ Belief in generalists and common sense. Belief in experts and technical solutions.}




\begin{tabular}{l|l|}
$\begin{array}{l}\text { Focus on decision process. } \\
\begin{array}{l}\text { Entrapreneurs are relatively free from } \\
\text { rules. }\end{array}\end{array}$ & $\begin{array}{l}\text { Entrapreneurs are constrained by } \\
\text { existing rules. }\end{array}$ \\
\hline Motivated by achievenment. & Motivated by job security. \\
\hline Table 4: Key differences between weak and strong uncertainty avoidance
\end{tabular}

\subsubsection{Long-Term Orientation}

Long-term Orientation is another dimetion Hofstede addressed in his culture dimension theory. This consists of long-term orientation and short-term orientation. The long-term orientation dimension can be interpreted as dealing with society's search for virtue, focus on the future, and pay attention to learning and perseverance. Additionally, a culture with short-term orientation, generally has a strong concern with establishing the absolute truth.

\subsubsection{Indulgence versus Restraint}

Indulgence relates to a society that allows relatively free gratification of basic and natural human drives related to enjoying life and having fun. Restraint relates to a society that suppresses gratification of needs and regulates it by means of strict social norms.

\subsection{Organizational behavior}

Moorhead (1995) pointed that organizational behavior is a field of study that investigates the human behavior within an organization, like the interface between human behavior and the organization, for the purpose of applying such knowledge toward improving an organization's effectiveness.

Organizational behavior is being studied increasingly, and it applies the knowledge acquired by individuals and groups on behavior within an organization in order to make work more effective. Thus, organizational behavior is concerned with the study of what people do in an organization and how their behavior affects the 
organization's performance. As a result, organizational behavior is closely associated with topics such as decision-making, leadership, motivation, personality, productivity, human performance and management.

Robbins (2010) categories the study into three domains: individuals, groups and organization structures.

\subsubsection{Individual level variables}

Individuals are the basic units with the same direction, but each is different in terms of personality, education and experience. The challenge of an effective organization is to successfully match tasks. According to Ashim Gupta (2010), in an ideal situation, in order to approach tasks efficiently and conflict freely, managers should identify the tasks first, and then assign them to people who have the required skills. During this process, the most obvious characteristics that affect us include age, gender, abilities, personality characteristics, perception, values, and attitudes. These characteristics are examined in Robbins's (2010) study. He summarizes the individual level variables that affect employee behavior: biographical characteristics, abilities, values, attitudes, personality, emotions, perception, individual decision making, learning and motivation.

\subsubsection{Group level variables}

Group level is the second variant of organizational behavior. A group is composed of individuals, but people's behavior in groups is more complicated than the sum total of all the individuals acting in their own way. The group level variables that affect employee behavior include communication, leadership and trust, group structure, conflict, power and politics, and work teams (Robbins, 2010).

\subsubsection{Organizational system level variables}

Organizational system level is the highest level of organizational behavior. An organizational system or organizational structure is developed to determine how an organization operates and assists an organization in approaching its goals to allow 
for future growth. Just as people's behavior in groups is more complicated than the sum total of individuals acting on their own, so is organizational behavior more than the sum total of its member groups. The structures of an organization, the organizational culture, and the practices all have an impact on the organization system level variables. (Harrison Dia, 2004)

\subsection{Organizational culture and organizational behavior}

Culture plays numerous roles within an organization. In the first place, it gives organization identities, which means it creates boundaries between one organization and others, as well as individuals. Further, culture could transform individual self-interests into something bigger which coincides with an organization's goal. Additionally, since culture regulates the behavior of the employee by providing appropriate standards, it enhances the organizational system level. Finally, culture acts as a behavioral mechanism that guides and shapes the attitudes and behavior of employees. (Robbins, 2010)

The phenomenon of culture associated with employee behavior appears to be increasingly important in today's workplace. Research on the relationship between organizational culture and organizational behavior is becoming increasingly important. More and more studies have examined the relationship between organizational culture and organizational behavior. Researchers claim there is a positive relationship. In these studies, various methods have been applied, such as theoretical study, field study and empirical study and so on.

A study provided by Kotter and Heskett (1992) gave a good example on the relationship between organizational culture and organizational behavior. In their study, their conclusion can be categorized into two: a contingency model and a universal model. The contingency model indicated that better performing organizations have strong cultures, but only if the culture fits the organization's environment. In contrast, the universal model outlined that if an organization wants to behave well in the long term, it must have a culture focused on three constituencies: customers, employees, and stockholders. 
Further, cultural factors and personalities affect organizational behavior. According to Hofstede (2010), culture is one of the many variables that could contribute to explaining behavior. Hofstede outlines that organizational culture is composed of six dimensions which have significant impact on organizational functions, including power distance, individualism and collectivism, uncertainty avoidance, masculinity and femininity, long-term orientation, indulgence and restraint. Some variables in the relationship between culture and behavior are noteworthly since they might have significant influence: leadership, organizational strategy, and human resources. Together with organizational commitment, these would be interesting variable to disscuss in future study.

\subsection{Advantages organizational culture has on behavior}

In practice, people understand that enterprise culture has a significant impact on an organization, management, and the future development of business.

According to De (2007), organizational culture affects behavior in six aspects. First of all, organizational culture has as a guiding role. Organizational cultures not only clearly affect the highest or long-term objectives, but also target the organizational objectives as individuals' goals. The objectives set by the organization allow its members to feel the value of work and inspire the desire of succeeding.

Secondly, organizational culture restraints peoples' behavior. This refers to organizational culture constraints and set standards for members' behavior. For an organization, rules and regulations are necessary. Still, it is difficult to standardize individuals' every behavior.

The third aspect is the cohesive effect of the organizational culture. When a certain organizational value is recognized by the employees, it becomes social glue. Through this impact, employees will generate a sense of loyalty to the enterprise.

Fourth, organizational cultures have an impact on incentives. This refers to enterprise cultures have an effect that enables employees generate a fore ahead emotionally. Promoting an enterprise culture is the process that helps employees 
looking for the sense to work and to establish social behavior. Through this process, employees can form common values and behaviors.

A radiation effect is the fifth aspect. Enterprise culture not only affects inside an organization, but also has an impact on society through various channels. People understand the deeper values of an organization through symbols, advertising, architecture, products and services. There are many channels to radiate this to society for instance media and public activities.

The sixth and final aspect is innovation. Excellent enterprise culture provides a working environment that inspires innovation, encourages difference, and tolerates failure. The most typical example is Google; innovation has become Google's Survival Guide.

In addition, the advantages organizational culture has on behavior is also reflected in leadership management. When making decisions, leaders have to confront many complex challenges. A leader's success depends on various factors, for instance on his knowledge and understanding of the organizational culture. The leader who understands his organization's culture and takes it seriously is capable of predicting the outcome of his decisions in preventing any anticipated consequences. It is notable that most human behavior is learned through imitation. In order to get employees to behave as expected, leaders' example is indispensable.

In addition, Schein (2004) states that leaders' success depends on sending and shaping correct contents about their priorities, values and beliefs. Once the culture is established and accepted, it will become a strong leadership tool. It will associate the leaders with the beliefs and values of an organization and its members and helps leaders to guide them. 


\section{CASE STUDY}

\subsection{Case Overview}

The case company JUNHE is one of the oldest law firms in China, and it is dedicated to providing first-class business and litigation legal services on the global scale. JUNHE's headquarters is in Beijing, and it has offices in Shanghai, Shenzhen, Guangzhou, Dalian, Haikou, Hong Kong, Silicon Valley and New York. The company has six hundred employees, and the working languages include Chinese (including Mandarin, Shanghai dialect, Cantonese), English, Japanese, and Korean.

Since the case company is a partnership law firm, the highest authority is the partner conference. Under the partner conference is the management committee, which is the executing agency for the partner conference. It is also responsible for daily management. In addition, there are nine parallel departments including the business management department, the research department, the training department, the marketing department, the financial department, the human resource department, the administration, the IT department, and the culture and entertainment department.

The researcher chose the company to be the study case because the researcher worked there as an intern for a year. The permission to investigate the cultural influences on employees was given by the head of administration.

\subsection{Organizational culture}

In order to do an in-depth analysis of corporate culture, many scholars have proposed a structural model or theory of corporate culture. For instance, Deal and Kennedy (1982) state that organizational culture consists of four factors: values, heroes, rituals, and culture network; Hofstede (2010) provides an onion model to cover the total concept of culture as was mentioned in Chapter 3.

By summarizing Deal and Kennedy's (1982) theory and Hofstede's (2010) theory, the researcher divides organizational culture into three levels (see Figure 3). The 
most superficial level is symbols. This level of the culture is visible, and that is why this part of the culture can be observed easily. The middle level is rituals. Rituals cannot be observed directly, but the middle level reflects the standards and constrains of organizational behavior. The core level is represented by values, and this part is the invisible side of culture, which includes attitudes, beliefs, interaction and other concealed features of culture.

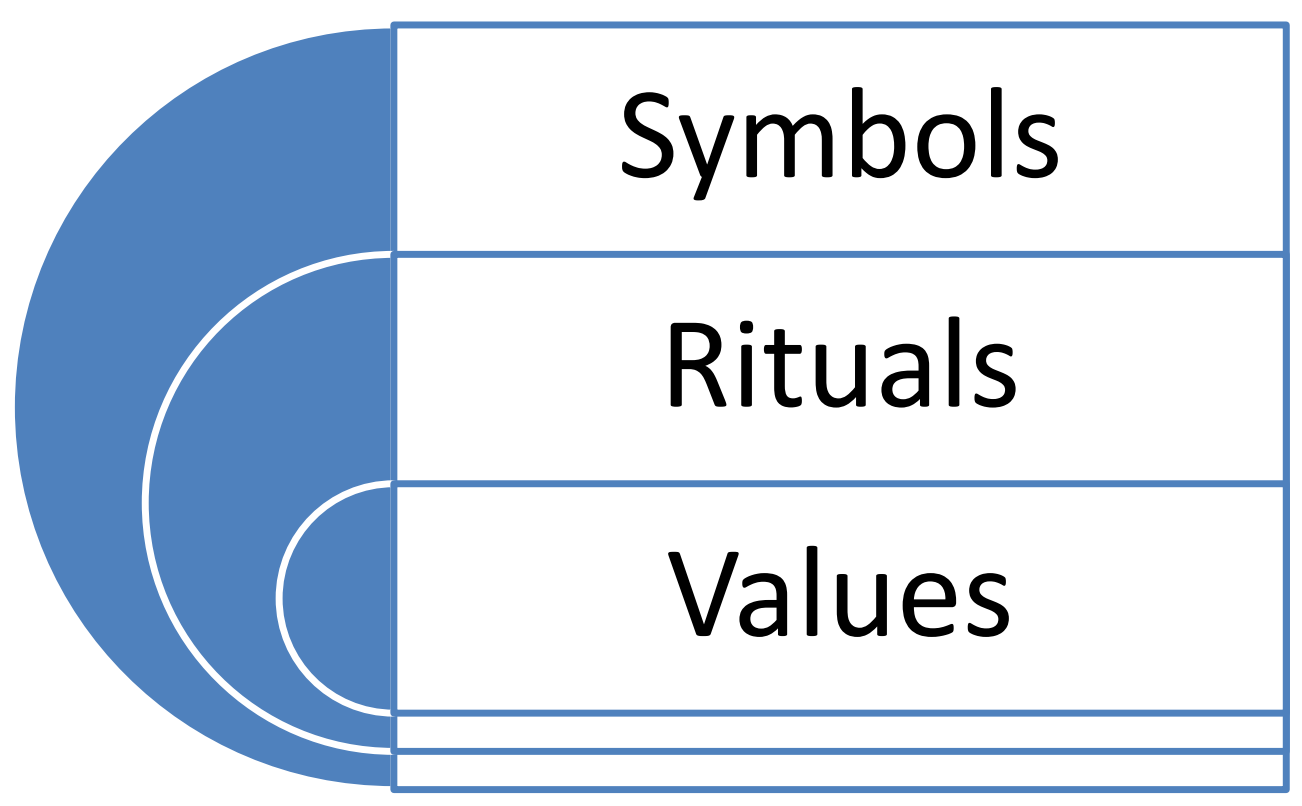

Figure 3: Structure diagram of organizational culture

\subsubsection{Symbols}

A symbol within an organization is any object that stands for ideas, visual images, beliefs, or actions. Usually, symbols formed with words, sounds, gestures, or images and are used to convey ideas and beliefs. At management level, symbols are mainly reflected in the following aspects: organizational logo, charity, office design, and media. This is the highest concentration of external corporate culture symbols. (Rafaeli;ym., 1999)

The representative factors of symbols in the case company are the logo and charity. The organizational logo states the first impression of the organization. It is the first information provided by the organization and shared with others. The basic organizational logo of the case company is JUNHE (see Figure 4). It comes from 
one of the teachings of Confucius: Cohered by true hearts. It is the founder's spirit, but also is the common spirit of the organization. A logo is a sign of an organization or its services, and it is a legally protected brand. Speaking from the perspective of management, a logo is an important part of the whole organization. That is, on the one hand, a logo is an important feature of the product or services. In order to expand market share, gain greater efficiency, certain logo awareness could help a lot. On the other hand, a trademark carries out a company's vision.
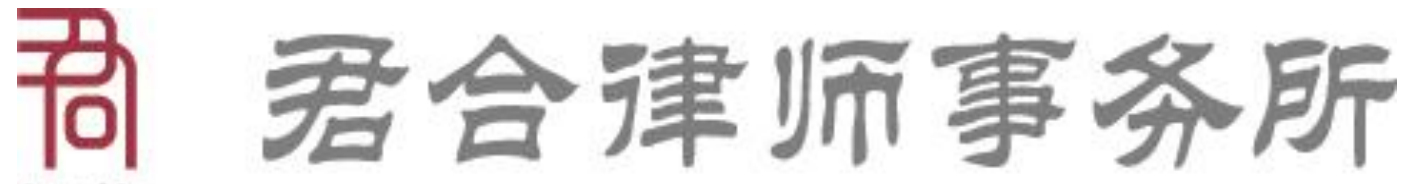

JUNHE

Figure 4: Logo of case company

Charity is another non-negligible part of the culture in symbols. As an influential organization in China, the case company is well aware of its social responsibilities. Thus, the case company puts a lot of effort and resources to support educational programs, scholarships, providing legal services and participation in public welfare. In order to provide a better education environment and brighter future for the younger generation, the case company provides service and support for many projects including donations to schools and participation with non-profits partners.

These characteristics in symbols convey to employees that the case company's values are cooperation, trust, and equality. By continuing to express the culture in the case company, the symbols represent the culture to its employees.

\subsubsection{Rituals}

Rituals are the regular culture interaction models and normative manners formed in long-term culture activities. They provide a code of conduct for certain situations, for instance in terms of language and dress code. Different rituals reflect the different characters and traditions within an organization. Obviously, rituals demonstrate the effectiveness of an enterprise in the construction and development of their own culture. (De, 2007) 
The case company has a very systematic code of conduct consisting of several aspects. Office dress code lists the standards of dressing in each situation. For instance, when meeting with customers, an employee should wear a suit, and shorts and jeans are forbidden. According to office rituals, employees should be civilized, polite, enthusiastic and friendly during office hours. They should use polite language when work at the front desk and answering the phone. Office security is another aspect. It outlines that employees should keep their personal belongins safely. In addition, employees should not leak confidential files and data which have information about the firm or customers. Employees also owe a duty to update their personal information to the human resource department once it has changed. Finally, the case company provides benefits for every employee, such as birthday gifts, annual physical examination, and cultural and sports activities.

Rituals are also reflected in some other details, such as e-mail specifications, paper mail format, usage of conference rooms, and the environment of the office.

Compared to the symbolic level, rituals regulate the behavior of employees more directly through a system, which provides a code of conduct to be observed in organizational joint activities. In the case company, each job has clear rules and procedures. The rules and procedures constraint the behavior of the employees and ensure the entire organization operates orderly and efficiently. In addition, there are some personalized regulations that better reflect the characteristics of a company's management and culture and affect employee behavior. For example, in order to improve the level of business, the case company has established "JUNHE FUNDS" to support employee training and study abroad. Every employee can apply for funds to study abroad.

Rituals are another way to transmit organizational culture to employees. Through the effective implementation of norms of behavior, the visions and values of an organization can be accepted easily, and the cohesion of an enterprise will be effectively improved. 


\subsubsection{Values}

Values can be understood in terms of binaries, for example, evil versus good, dirty versus clean, dangerous versus safe, and forbidden versus permitted. To better understand the case company's cultural values, the researcher applies Hofstede's culture dimension theory to measure the target company's cultural values. Figure 5 below shows the relations between dimensions and a given value.

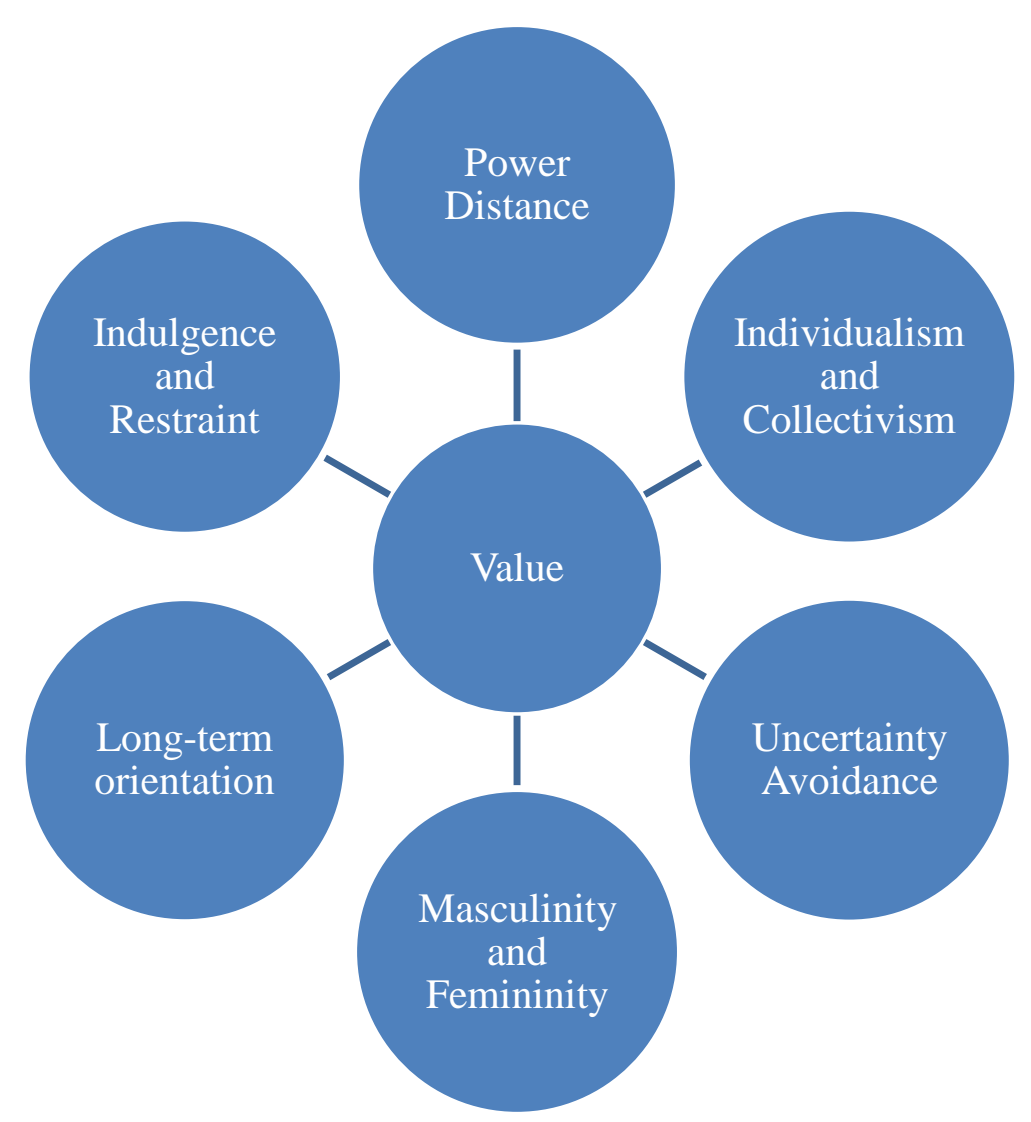

Figure 5: Relations between dimensions and a given value

\subsection{Culture dimensions measurement}

A given value is the stable element in culture. The present research on values starts from the measurement of values. Measuring values from people's behavior is unclear and ambiguous, since values are affected by various factors. The six common problem areas listed by Hofstede represent the dimensions of culture in order to determine its influence of organization. A dimension is an aspect of culture which can be measured and managed. 
Before the researcher discovers the cultural influence of values in the case company, interviews and observations give some clues to understand the target company's culture.

\subsubsection{Power distance}

To better understanding the power distance in the case company, the researcher has categorized power distance according to four aspects involving organizational structure, communication, decision making, and leadership. Interviews and observation will give some hints about how power distance appears within the company.

Since the case company is a partnership law firm, the highest authority is the partner conference. Under the partner conference is the management committee, which is the executing agency for the partner conference. This-is illustrated in Figure 6. It is helpful for the researcher to identify and evaluate power distance through the structure.

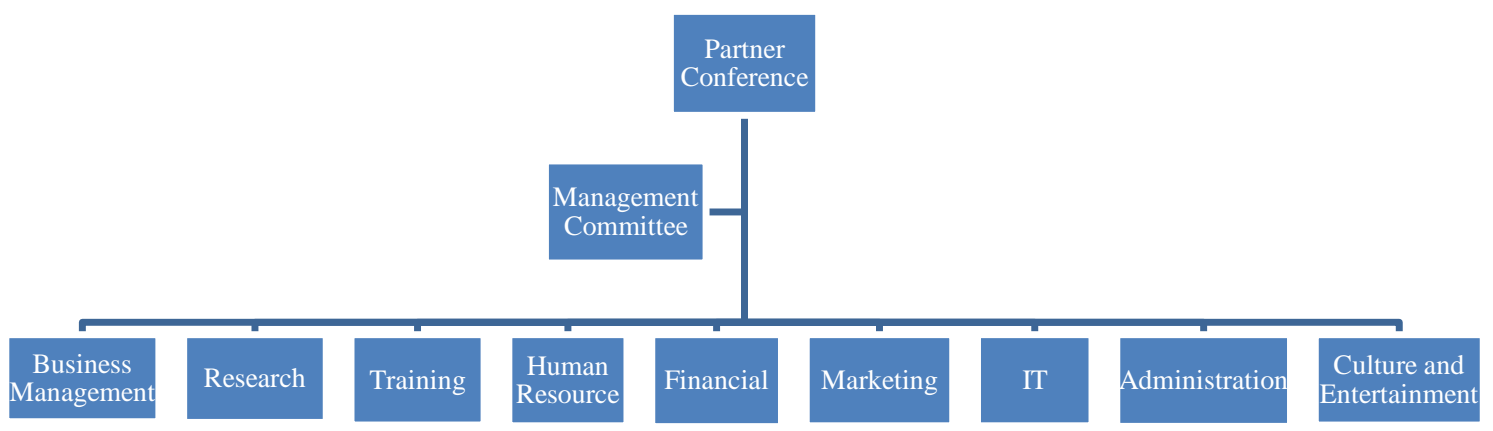

Figure 6: Organizational structure of the case company

The structure of the company is very simple. It has three vertical levels: the partner conference, the management committee, and the departments on the third level. It seems that the case company is highly centralised, and top managers make all the decisions and lower-level managers merely carry out the top management's directives. Because of the case company's unique management strategy, the partner conference has central authority. Still, the partner conference leaves a great amount 
of autonomy to each deparment. Implementing autonomy gives employees space to show their skills and aspirations, and provides opportunities for them to make some achievements on the stage of management. The more abilities employees have, the more effort they should put on external competition. Additionally, it could further enhance job satisfaction, autonomy leads to higher employee performance because supervision is more distant and there are more opportunities for personal initiative.

In addition, communication between superiors and subordinates is another aspect that reflects the power distance. Communication is not only exchange of information, but it can also express attitudes and motivate others. In the work place, people communicate among subordinates, among superiors, and among managers to express their opinions, ideas, and attitudes.

The description of communication in the case company is based on an interview and observation. The employee interviewed told that in most cases, instead of formal communication, communication is informal in the work place. Also, subordinates are not afraid to express disagreement with their superiors. If there is a problem, it can be brought directly to the superiors and solutions can be discussed.

In addition, decision making should be considered in relation to power distance.

Choosing one from the available options is decision making. In the case company, the interviewees told that the main decisions, for example strategies, are made by the partner comference, which is the highest level of the company. Decisions are then communicated directly to the subordinates. If the decision is adopted, subordinates can provide feedback and the decision may undergo adjustments. Moreover, the interviewees said that privileges exist at the organization, for instance, the main decision maker's opinions or decisions could influenced by personal feeling. Additionally, in the process of implementing decisions, subordinates should completely obey the superiors and complete the decisions accurately.

\subsubsection{Individualism and collectivism}

Individualism and collectivism is another aspect in values, and it reflects whether employees prefer working individually or within a group (Geert, et al., 2010). In 
order to measure this dimension, the researcher categorized it into two parts: working conditions upon individual work and group work, and conflict solving.

Working conditions contain individual factors and group factors. This involves personal time, freedom, challenge, training, physical condition, use of skills, and communication. Personal time is time left outside work for employees' family life. On the other hand, Freedom, then again, refers to the idea that employees should have freedom to adapt their own approach to their jobs. Challenge refers to the idea that their jobs should be challenging enough, so that employees can feel a sense of achievement. Training relates to the notion that there should be training opportunities available, so that employees can improve their skills or learn new skills. Physical conditions, on the other hand, refer to an organizations work spaces; for example, good ventilation and lighting, and adequate work space. Use of skills relate to the idea that employees should be able to fully use their skills and abilities in their jobs. Finally, communication refers to the notion that employees should communicate with each other. It also means that there are different means and media for communication, for example email, telephone and face-to-face communication.

Based on the observation, the researcher noticed that personal time and freedom were not much concerned by the employees in the case company. Generally, personal time is corretaled with the amount of work, and sometimes employees have to sacrifice their personal time to work overtime Most of the employees are fine with this, since they can shift the overtime hours to another day. For example, if an employee has worked for one hour of overtime, he/she can transfer that hour to the next day as a regular work hour. In addition, freedom is another factor the case company's employees are not concerned with. Instead of freedom, the employees prefer to be told what to do.

The researcher also asked the interviewees to select those factors that would be important to their present job. Most interviewees chose "challenge" as the most important factor. Training, physical conditions, and communication were preferred as well. The interviewees told that most employees treat their job as a "job", dot have to emphasize the sense of missions. To the employees, a pleasant working 
atmosphere, a comfortable working environment, the opportunity to upgrade their skills, and sufficient communication are more important. Generally, challenge, training, physical conditions and communication have a common point, that is motivation. Motivation is the processes that stimulate an individual's emotions.

Conflict solving in the workplace is another important issue. Robbins (2010) defined conflict as follows:

Conflict as a process that begins when one party perceives that another party has negatively affected, or is about to negatively affect, something that the first party cares about.

In workplaces, conflicts may result from many reasons such as poor communication, different values, personality clashes, and poor performance between people. Based on the culture of the case company, there are two ways that the case company advocates employees to solve conflicts. The first is collaboration, which means the two sides of a conflict work together to find a solution that has benefits for both sides. The other one is compromise, which is finding a middle ground, and each side of the conflict has sacrificed part of their benefit in order to reach equilibrium.

\subsubsection{Uncertainty avoidance}

Uncertainty avoidance within an organization is reflected in formal laws and informal rules controlling the rights and duties of superiors and employees, and additional, internal regulations controlling the work process (Geert, et al., 2010). In order to measure uncertainty avoidance in the case company, the researcher analyses the rules and technologies supporting it.

Before conducting an interview, the researcher told the interviewees that uncertainty avoidance should not be confused with risk avoidance. Risk is often expressed as probabilities that a particular issue will happen; usually it focuses on something specific. Uncertainty has no object, and it could be understood as a situation in which anything will happen and we have no idea what it is. 
Rules are set to prevent uncertainties in the behavior of other people. In the case company, the rules are relatively consistent with the company's interests and corporate culture. In the case company's management handbook, it is mentioned that the rules and regulations are people oriented. The partner conference will also continue to advocate this positive, cohesive culture that encourages employees to participate.

Technology, from the most primitive to the most advanced, helps people to avoid uncertainties caused by nature. The case company has developed ways to alleviate uncertainties through particular software and equipment. The software contains an outsourced enterprise business management solution. This solution comes with a variety of built-in capabilities. It gathers financial management, client and matter management, risk management, and business development into one system. The software has helped the case company to solve various unpredictable challenges. Furthermore, based on the contents of work, the case company provides equipment for each employee. The equipment includes a desktop, a laptop, and a cell phone. The devices are preconfiged, and the employees have no permission to install, uninstall, or operate any software or hardware unrelated to their job.

\subsubsection{Masculinity and femininity}

The fourth dimension is masculinity and femininity. Generally, it was associated most strongly with the importance attached to the following work goal items: earnings, recognition, advancement, challenge, manager, cooperation, living area and employment security.

Earning system is an important part of the organization system. The importance of earnings is not only reflected in personal efforts and rewards, but it is also reflected in incentive effects. It plays an important role in stimulating employee motivation, enhances cohesion, improves employee productivity, and promotes the development of production. Reasonable earnings not only could effectively stimulate their enthusiasm, initiative and motivate employees to strive for the business goals, but may also attract and retain high-quality human resources within an organization, especially in a highly competitive society. 
Challenging work refers to valuable work with certain difficulty; employees need to work seriously, hard, and creatively to complete it. The completion of such work allows an employee to get psychological rewards. Challengs at work can inspire employees' potential abilities, enhance self-confidence, and an employee can feel a sense of accomplishment and achievement. Challenging work can also motivate employees to acquire knowledge and skills, and enhance their abilities. Challenging work is the most effective way to inspire employees.

\subsubsection{Long-term orientation}

In all orgnizations, profit is the ultimate goal. In order to approach that, strategies are necessary. Long-term orientation or short-term orientation was defined from the beginning of the organizational strategy. In addition, long-term orientation and short-term orientation are also reflected in interpersonal relationships, investments, and market shares.

When considering law firms, instead of monthly, quarterly or yearly profits, long-term goals are more important. In 2010, the case company confirmed its development vision and goal in order to ensure the sustainable development of the firm. In the next five years, the company emphasizes specialization, branding and operating in the global markets. At the expense of immediate results, by implementing a strong marketing strategy, by increasing investments in development, by adjusting a consultancy service model and by other means, the company aims to maintain it existing business and increase its market share.

In addition, the internal interpersonal relationship is another main factor that reflects the culture of long-term or short-term orientation. According to Hofstede's culture dimensions theory (2010), in a short-term culture, an employee's loyalties vary with the business needs. On the contrary, in a long-term culture, an employee prefers to invest in lifelong personal networks. In the case company, the interpersonal relationships follow two principles: (1) a hedge between keeps friendship green; (2) fair to everyone. Business management should treat employees as fairly as possible. 


\subsubsection{Indulgence and restraint}

Indulgence and restraint reflect the satisfaction of well-being. This is defined by two main aspects: happiness and the importance of leisure. In practice, since the case company is a law firm, considering the special nature of the job, professional background should also be taken into account. Lawyers' work is very strict, hard, heavy, and requires lifelong learning. Thus, in the legal profession, indulgence is not acceptable.

In the case company, the researcher noticed that employees' actions are restrained by various norms and prohibitions. Also, any type of indulgence is never performed during work time. Especially, in front of the customers, self-restraint is more favoured and trusted. 


\section{DATA ANALYSIS}

The aim of this study is to find how organizational culture affects employee behavior. Organizational culture was into divided three parts: symbols, rituals, and values. It is noteworthy that values were categorized according to six dimensions: power distance, collective and individual, uncertainty avoidance, masculinity and femininity, long-term orientation, indulgence and restraint. The hypothesis, that employee behavior is affected by symbols, rituals, and the six dimensions of values, is tested through interviews and observation in the case company.

Symbols and rituals are measured based on observation. Put simply, symbols and rituals play a role that has the responsibility to transmit organizational culture to employees. Rituals are activities or standards that express and enhance the key values of an organization. Symbols, then again, represent the vision, motivation, and values of an organization. Thus, employees can learn organizational culture through these different forms.

In order to investigate how values impact the case company, the same questions were handed over to employees from different levels of the company. On the management level, the head of the administration was interviewed. On the subordinate level, two employees from the IT department accepted to be interviewed as a group. Answers by the management level and subordinate level were as follows.

Power distance

1. Is an employee afraid to express disagreement with their managers frequently?

Head of administration: Does not fear to express disagreement with superiors, currently has good communication channels, if there is a problem, it can be brought directly to the superiors and solutions can be discussed.

IT employees: Most of the administrative staff is not afraid, but not all of them. 
2. During work, is communication between subordinates and superiors informal or comfortable?

Head of administration: Most of the time it is comfortable.

IT employees: In some situations formality is preferred, but most of the time employees feel comfortable to communicate.

3. Dose privileges exist?

Head of administration: They may exist. For instance, the administrator of the management committee is the main decision maker. Personal feelings of the decision maker may affect his/her decisions.

IT employees: Yes, they do exist.

4. Should subordinates obey manager's plans accurately or interpret them freely?

Head of administration: subordinates should completely and accurately obey their superior's plans.

IT employees: We prefer to have freedom.

5. Do subordinates prefer to be consulted before a decision is made that affects their work or to be told what to do?

Head of administration: Usually, important decisions are made by superiors and then informed directly to subordinates.

IT employees: Most decisions are made by the management committee or the partner conference. The decision maker might ask opinions from the head of each department.

Table 5: Interviewees' answers concerning power distance

Question 1 and 2 in Table 5 indicate that the communication among subordinates and superiors. Even though the interviewees from different levels of the case company, the answers did not differ much. Generally the interviewees agree that the communication atmosphere is very comfortable. The case company's employees are able to express their disagreement and attitudes.

As questions 3 to 5 reveal, the decision making process is important. In the case company's culture, important decisions are made by the top level of the company and privileges may have an impact on decision making. In addition, managers 
prefer the subordinates to work accurately according to plans, whereas subordinates prefer freedom.

Individualism and collectivism

1. Try to think of those factors that would be important to you in your present job. (Personal time, Freedom, Challenging work, Training, Physical conditions, Use of skills, Communication)

Head of administration: Challenges

IT employees: Challenges, Physical conditions, Training

2. When there is disagreement and you need to present your own viewpoint, what will you do?

Head of administration: If it does not interfere with my interests, I will not have too much involvement. However, depending on the particular situation, I may provide my proposal.

IT employees: Finding compromise solutions.

Table 6: Interviewees' answers concerning individualism and collectivism

The answers for question 1 concerning individualism and collectivism were prepared during the interviews. During the interviews, the researcher asked the interviewees to select the ideal factors and multiple choices were allowed. Question 2 in the table illustrates the idea that conflicts should be solved according to the case company's culture. The IT employees and the head of administration's replies are showen in Table 6.

The questions were asked to determine the cultural impacts on individualism and collectivism. All of the interviewees chose "challenge" as one of their work goals. Challenge enhances an employee's independence from the organization. If an organization continuously gives an employee unchallenging work it may appear that the organization cares for the employee. However, this is not true. Essentially, this means the organization does not give the employee opportunities to develop and progress. Thus, the employee will always remain at the same level. On the contrary, accepting challenging work relates to improvement. An employee will learn in order to complete such work and improve his or her knowledge and skills. 
If compare to challenging work, training offers opportunities to improve and promote individual learning. Training can also enhance an employee's sense of loyalty, and enhance organizational profitability. Moreover, physical conditions refer to things the organization does for the employees. The answers to Question 2 show that in the case company's culture, no one acts strongly against others. Therefore, finding compromises and proposals are acceptable solutions.

Masculinity and femininity

1. Try to think of those factors that would be important to you in your present job. (Earnings, Recognition, Advancement, Challenge, Cooperation, Living area, Employment security)

Head of administration: Earnings

IT employees: Earnings, Recognition, Challenge, Cooperation

Table 7: Interviewees' answers concerning masculinity and femininity

In Table 7, the interviewees' answers vary. The question was asked to determine the cultural impacts on masculinity and femininity. Note that the work goal challenge was also associated with the individualism dimension. The other goals are associated only with masculinity and femininity. For the given answers, all of the interviewees select earnings as an important aspect. The reasons they select earnings could be summarized as follows. Firstly, let talents come to the fore, to reward outstanding employees. A good earning system ensures the strong become stronger and encourages the weak to keep pace with the strong. It also attracts talented employees. Finally, employees work harder when the interests of a company and an individual are interrelated.

Two interviewees also chose recognition, challenge and cooperation as important factors. Challenge was mentioned in an earlier chapter. Recognition is one of the driving factors that motivate people to work. Lack of recognition will lead to the loss of ideas, reduce the employee's efforts and even lead to slacking. Cooperation has the same impact. Good cooperation can increase strength and improve efficiency. Reasonable division of labor could enhance overall competitiveness. 
Uncertainty avoidance

1. Job stress: how often do you feel nervous or tense at work?

Head of administration: Not often, because the current work does not constitute of too much pressure, except sometimes the quantity of work is relatively large, and there is need to sacrifice some personal time to work overtime.

IT employees: Once in a while. Usually we feel nervous when fixing an organizational system and unknown problems occurre.

2. How do you deal with ambiguity and chaos?

Head of administration: It is intolerable.

IT employees: We can tolerate a little bit of ambiquity, but not chaos.

3. How long do you think you will continue working for JUNHE?

Head of administration: At least 5 years.

IT employees: A year or two, for future development.

4. Should company rules be broken if an employee thinks this is in the company's best interest?

Head of administration: Currently, rules are consistent with the company's interests and organizational culture.

IT employees: It depends on the situation.

5. Do you focus on the content of a decision or on the decision making process?

Head of administration: Whether the process or outcome, are concerned about.

IT employees: The content of a decision.

6. Are you motivated by a sense of achievement or employment security?

Head of administration: 60 percent by achievement and 40 percent by employment security.

IT employees: Achievement.

Table 8: Interviewees' answers concerning uncertainty avoidance 
Questions 1 in Table 8 relate to the degree of job stress. The answer from the head of administration points out that there is not too much pressure in present job. However, the IT employees told that they feel tense when facing unknown bugs, and when fixing a system, since system tests might be insufficient. Occupational stress is a double-edged sword. On the one hand, appropriate occupational stress can motivate employees to work hard. On the other hand, too much pressure will lead to a series of adverse reactions, for example job dissatisfaction, boredom, no sense of responsibility, and result in reduced efficiency.

The answers from 2 to 6 in the table all indicate strong an uncertainty avoidance in the organizational culture. According to the answers, the case company has created many regulations, procedures and practices to deal with uncertainty. The decisions are usually based on a decision-making procedure. Additionally, they believe that most problems can be solved with regulations. The interviewees have no intention to leave the company in the short term. They are all motivated by the job achievements. Moreover, employment security also plays a role. From the organizational management perspective, uncertainty avoidance affects the organizational structure.

Long term orientation

1. Try to think of those factors that would be important to you in your present job. (Thrift, Respect for tradition, Protecting one's "face", Achievement, Self-discipline)

Head of administration: Achievement, self-discipline IT employees: Freedom, Rights, Achievement, Self-discipline

2. Importance of this year's profits or profits ten years from now?

Head of administration: In the legal profession, both of them are important, but long-term profit is more concerned.

IT employees: Ten years from now.

3. Personal loyalties vary with business needs or investment in lifelong personal networks?

Head of administration: Personal networks 
IT employees: Personal networks

4. Focus is on the "bottom line" (the results of the past month, quarter, or year) or market position?

Head of administration: Market position

IT employees: Both.

Table 9: Interviewees' answers concerning long-term orientation

Long-term orientation in culture reflects the differences in working objectives. In

Table 9, question 1 indicated that the important factors in long-term orientation that motivated their work. All of the interviewees choose achievement and self-discipline. The employee feels a sense of achievement always when the task is done, through use of existing knowledge and skills. The completion of the work usually associated with the generation of a series of new results, even without the invention and innovation, to complete the work with a certain difficulty in it, will make employee feels a sense of achievement. Self-discipline refers to individuals in the community to act to be self-restraint, self-control, self-reflection, and self-correcting binding.

The answers for question 2 to 4 point toward the idea that long-term orientation is deeply rooted in case company. It also reflected in company's strategies. Instead of short-term profits, the case company focused on long-term objectives and market positions. Besides company's objective, interpersonal relationship also influenced by long-term orientation. All of the interviewees prefer to develop a personal network at work place.

Indulgence and restraint

1. Happiness: "taking all things together, would you say you are very happy, quite happy, not very happy, or not at all happy."

Head of administration: Quite happy.

IT employees: Quite happy.

2. Importance of leisure: leisure should are relatively free based on human nature (desires to enjoying life and having fun) or curbed and regulated by 
strict norms?

Head of administration: Leisure should be curbed and restrainted.

IT employees: Leisure should are relatively free.

Table 10: Interviewee's answers from question theme indulgence and restraint

The question 1 and 2 in Table 10 indicated that the attitudes about the well-being upon case company's culture. Generally interviewees feel quite happy at present job. It follows that they have adapted to the present work, norms, rules, wages, they feel satisfied with the job. Though occupational stress happens, but it also promotes them to make progress. All this predicts relatively quite happiness. The answer goes rather differ on question 2. One interviewee agrees that leisure should be curbed and restrained, but the others do not agree.

In fact, there is no evident support that indulgence and restraint have impact on people's behavior in the workplace. It all related to that employee could act as he/she pleases; indulges in leisurely and fun-related activities. Since the activities are all beyond the work, it should not take into account. 


\section{CONCLUSION}

The literature review of this thesis shows that there are three levels in organizational behavior. The first level is individual behavior, the second level is group behavior, and the third level is organizational system level. The individual behavior includes biographical characteristics, ability, values, attitudes, personality, emotions, perception, individual decision making, learning and motivation. The group behavior consists with communication, leadership and trust, group structure, conflict, power and politics. The organizational system level involves organizational culture, human resource policies and practices, and organization structure and design.

However, the case study found that not every behavior was affected by the organizational culture. Still, some part of employee behavior has a strong correlation with culture. The three levels of the organizational culture include symbols, rituals, and values; each level has unique impacts on behavior. Symbols have impacts on motivating employees, and delivering a company's vision and values to its employees. Rituals set behavior standards and enhance the key values to employees. Meanwhile, symbols and rituals stand for a mean of cultural dissemination.

In addition, values as the core level of the organizational culture have the most significant impact on employee behavior. Values include six dimensions, and each dimension represents the different aspects of organizational culture. The first dimension is power distance. Power distance in culture reflects the organization structure and design. It also has impacts on communication, attitude expression and decision making. The second dimension individualism and collectivism have impacts on the working goals upon individual and group work, such as individual learning, ability, and values. It also shows the impact on conflicts solving. The third dimension, masculinity and femininity, indicates that the pursued working goals are based on gender characteristics. Those working goals show the third dimension has impact on motivation. It is worth noting that reward system, which belongs to human resource and practices, is also affected by the dimension of masculinity and femininity. The fourth dimension, uncertainty avoidance, shows this part of culture 
not only could motivate employee by job stress and challenge, but also could defeat an employee with it. The fifth dimension is long-term orientation. The research on it shows the effects on motivation, individual learning, and group decision making. The sixth dimension, indulgence and restraint, outlines the employee's attitude of well-being. Yet there is no evidence that this dimension has an impact on employee behavior.

All in all, the organizational culture's impacts are mainly reflected in motivation, promote individual learning; communication; and enhance organizational values; group decision making; and conflict solving. 


\section{DISCUSSION}

\subsection{Limitations}

The aim of this study was to find out how organizational culture affects employee behavior.

Because of limited resources and time, only three employees were interviewed: the head of administration and two people from the IT department. Due to the limited number of interviewees, all aspects might not have been covered.

Another limitation is that the questions asked during the interview did not cover all sides of organizational culture, and there was not much time for further questions. The data might not be collected completely and may lead to ambiguity. In addition, observations are subjective, and it is difficult to compare the outcome from different people.

Finally, the present study focused on people's behavior in an organization, but organizational culture is not the only factor that affects employee behavior. For instance personality, ethinic background and religion may affect an individual's behavior.

\subsection{Validity and reliability}

It is important to considere reliability and validity. Joppe (2000) defines reliability as follows:

The extent to which results are consistent over time and an accurate representation of the total population under study is referred to as reliability and if the results of a study can be reproduced under a similar methodology, then the research instrument is considered to be reliable.

The reliability of this study is measured according to the interviews and observation conducted in the case company. The case company is one of the oldest law firms in China with a strong organizational culture. On the other hand, the researcher interviewed three employees in the case company under the permission of the head 
of administration. The interviewees have different educational backgrounds and work experience. In addition, the researcher observed employee behavior directly without any influence on it. All of the data was analysed carefully; therefore, the study is reliable.

Validity in research declares how truthful the research results are. Golafashani (2003) defined validity as it is measured for demonstrating whether the research is truly processed as it is intended to be.

In this study, the data were collected by interviews and observations. Although, considered the researcher has worked in the case company, the process of data collection is quite fair without any personal judgement. Furthermore, the research result strongly supported the researcher' assumption, and therefore the study is valid.

\subsection{Suggestions for future study}

The studies correlated with the cultures that have influenced on people's behaviors within an organization could be further investigated. As mentioned earlier, the fact that the number of interviews were limited due to constraint time and resources; the questions in interviews may not cover all aspects of the organizational culture. Therefore, further studies on culture could pay more attention in identifying all aspects of organizational culture. Moreover, further studies could also take other factors into account, such personalities and ethnic culture. 


\section{REFERENCES}

Published References

Barney, J. B. (1986). Organization culture: can it be a source of sustained competitive advantage?

De Zhang \& Wenjun Pan (2007). Corporate culture.

Deal, T.E. \& Kennedy, A. (1982), Corporate Cultures: The Rites and Rituals of Organizational Life, Addison-Wesley, Reading, MA.

Geert Hofstede \& Gert Jan Hofstede \& Michael Minkov (2010). Cultures and Organizations.

H. J. Leavit. (1964). Managerial Psychology.

Innes, James (2012). The interview book: your definitive guide to the perfect interview.

Joppe, M. (2000). The Research Process.

Kotter, J., \& Heskett, J. (1992). Corporate Culture and Performance.

Moorhead, G., \& Griffin, R. W. (1995). Organizational behavior: Managing people and organizations.

Robbins, Stephen P. \& Judge, Timothy A. \& Campbell, Timothy T. (2010). Organizational behaviour.

Schein, Edgar, H. (2004). Organizational culture and leadership.

Woodwell, Douglas (2014). Research foundations: how do we know what we know?

Electronic References

Anat Rafaeli \& Monica Worline (1999). Symbols in Organizational Culture. Retrieved from: http://iew3.technion.ac.il/Home/Users/anatr/symbol.html 
Ashim Gupta (2010). Individual behavior in organization. Retrieved from:

http://practical-management.com/Organization-Development/Individual-Behavior -in-Organization.html

Cui Xiaoming \& Hu Junchen (2012). A Literature Review on Organization Culture and Corporate. Retrieved from:

Performancewww.sciedu.ca/journal/index.php/ijba/article/download/863/4157

Definition: Lawyer. Retrieved from:

http://www.oxforddictionaries.com/definition/english/lawyer

Harrison Dia (2004). Assessing Individual and Group Behavior. Retrieved from: http://www.sagepub.com/upm-data/5050_Harrison_Chapter_3.pdf

Irina Nicolau, Adina Musetescu (2012). The influence of lifelong programs on the organizational culture and Performance. Retrieved from:

http://www.sciencedirect.com/science/article/pii/S187704281201470

Nahid Golafshani (2003). Understanding Reliability and Validity in Qualitative Research. Retrieved from: http://www.nova.edu/ssss/QR/QR8-4/golafshani.pdf Organizational culture: The effect of behavior on performance. Retrieved from: http://www.gecapital.eu/en/docs/GE_Capital_Overview_Organizational_Culture.p df

Organizational Structure and culture. Retrieved from: http://zh.scribd.com/doc/23295893/Organizational-Structure-and-culture-Hofstede -s-four-dimensions\#scribd

Sonja Treven \& Matjaž Mulej \& Monty Lynn (2008). The impact of culture on organizational behavior. Retrieved from: https://www.efst.hr/management/Vol13No2-2008/2-Treven\%20Mulej\%20Lynn.p df 


\section{APPENDICES}

Interview sheet

Topic: Organizational Culture and Employee Behavior

Author: Tianya LI

Date of interview:

Interviewee's position:

Theme: Power Distance

1. Is an employee afraid to express disagreement with their managers frequently?

2. During work, is communication between subordinates and superiors informal or comfortable?

3. Dose privileges exist?

4. Should subordinates obey manager's plans accurately or interpret them freely?

5. Do subordinates prefer to be consulted before a decision is made that affects their work or to be told what to do?

Theme: Individualism and collectivism

1. Try to think of those factors that would be important to you in present job.

- Personal time

- Freedom

- Challenging work

- Training

- Physical conditions

- Use of skills

- Communication

2. When there is disagreement and you need to present your own viewpoint, what will you do? 
Theme: Masculinity and femininity

Try to think of those factors that would be important to you in present job.

- Earnings

- Recognition

- Advancement

- Challenge

- Manager

- Cooperation

- Living area

- Employment security

Theme: Uncertainty avoidance

1. Job stress: how often do you feel nervous or tense at work?

2. How do you treat with ambiguity and chaos?

3. How long do you think you will continue working for JUNHE?

4. Should company rules be broken if an employee thinks this is in the company's best interest?

5. Do you focus on the content of a decision or on the decision making process?

6. Are you motivated by a sense of achievement or employment security?

Theme: Long-term orientation

1. Try to think of those factors that would be important to you in present job.

- Persistence

- Thrift

- Respect for tradition

- Protecting one's "face"

- Freedom

- Rights

- Achievement 
- Self-discipline

2. Importance of this year's profits or profits ten years from now?

3. Personal loyalties vary with business needs or investment in lifelong personal networks?

4. Focus is on the "bottom line" (the results of the past month, quarter, or year) or market position?

Theme: Indulgence and restraint

1. Taking all things together, would you say you are very happy, quite happy, not very happy, or not at all happy?

2. Leisure should are relatively free based on human nature or restraint and regulated by strict norms? 